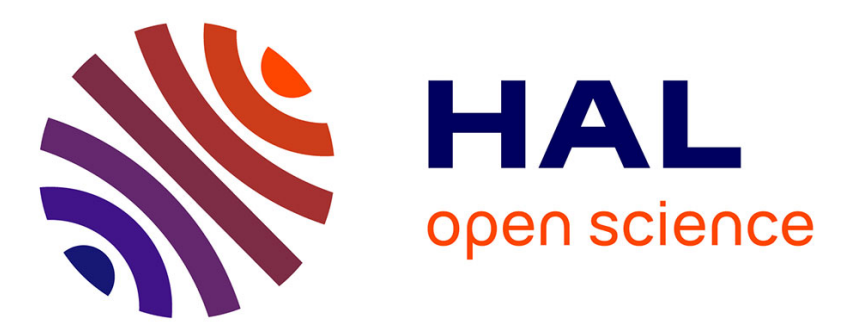

\title{
Is there a 'pig cycle' in the labour supply of doctors? How training and immigration policies respond to physician shortages
}

\author{
Xavier Chojnicki, Yasser Moullan
}

\section{- To cite this version:}

Xavier Chojnicki, Yasser Moullan. Is there a 'pig cycle' in the labour supply of doctors? How training and immigration policies respond to physician shortages. Social science \& medicine, 2018, 200, pp.227237. 10.1016/j.socscimed.2018.01.038 . hal-01793451

\section{HAL Id: hal-01793451 https://hal.science/hal-01793451}

Submitted on 18 Dec 2018

HAL is a multi-disciplinary open access archive for the deposit and dissemination of scientific research documents, whether they are published or not. The documents may come from teaching and research institutions in France or abroad, or from public or private research centers.
L'archive ouverte pluridisciplinaire HAL, est destinée au dépôt et à la diffusion de documents scientifiques de niveau recherche, publiés ou non, émanant des établissements d'enseignement et de recherche français ou étrangers, des laboratoires publics ou privés. 


\title{
Is there a 'pig cycle' in the labour supply of doctors? How training and immigration policies respond to physician shortages
}

\author{
Xavier Chojnicki ${ }^{\mathrm{a}, *}$, Yasser Moullan ${ }^{\mathrm{b}, \mathrm{c}, \mathrm{d}}$ \\ ${ }^{\text {a } L E M-C N R S, ~ U n i v e r s i t y ~ o f ~ L i l l e ~ a n d ~ C h a i r e ~ T r a n s i t i o n s ~ D e ́ m o g r a p h i q u e s, ~ T r a n s i t i o n s ~ E c o n o m i q u e s, ~ F r a n c e ~}$ \\ ${ }^{\mathrm{b}}$ Center of Economics and Management of Indian Ocean (CEMOI) from University of Reunion Island, France \\ ${ }^{\mathrm{c}}$ International Migration Institute (IMI) from University of Oxford, UK \\ ${ }^{\mathrm{d}}$ Institute for Research and Information in Health Economics (IRDES), France
}

\begin{abstract}
Many OECD countries are faced with the considerable challenge of a physician shortage. This paper investigates the strategies that OECD governments adopt and determines whether these policies effectively address these medical shortages. Due to the amount of time medical training requires, it takes longer for an expansion in medical school capacity to have an effect than the recruitment of foreign-trained physicians. Using data obtained from the OECD (2014) and Bhargava et al. (2011), we constructed a unique country-level panel dataset that includes annual data for 17 OECD countries on physician shortages, the number of medical school graduates and immigration and emigration rates from 1991 to 2004. By calculating panel fixed-effect estimates, we find that after a period of medical shortages, OECD governments produce more medical graduates in the long run but in the short term, they primarily recruit from abroad; however, at the same time, certain practising physicians choose to emigrate. Simulation results show the limits of recruiting only abroad in the long term but also highlight its appropriateness for the short term when there is a recurrent cycle of shortages/surpluses in the labour supply of physicians (pig cycle theory).
\end{abstract}

\section{Introduction}

The international shortage of physicians is a major concern in developed countries around the world. These shortages will probably increase over the coming decades due to expected increases in the demand for health care driven by the forthcoming ageing population and a reduced physician's workforce caused by the upcoming retirement of baby boomers. The European Commission forecasts a shortage of one million health professionals (not only physicians) in the EU around 2020 (WHO, 2013). According to predictions, the US may face a deficit of 124,000 physicians by 2025 (AAMC, 2008). Health workforce planning primarily aims to achieve a proper balance between the demand and supply of different categories of health workers for both the short and longer term.

To respond to shortages, governments generally consider three policy options. The first is to train a sufficient number of medical graduates to replace a shrinking health workforce. The second is to recruit internationally physicians that have been trained abroad. The third is to increase the retention of the health workforce.

However, these training, immigration and retention strategies each take a different time to enact. Given the duration of training in medical schools, the impact of increasing the number of medical students to address any shortages is only realized between seven to ten years after the decision has been made. This time delay between the appearance of the shortage and the supply of medical doctors is illustrated by a theoretical economic framework called the "pig cycle" or "cobweb theory"(Coase and Fowler, 1935, 1937; Ezekiel, 1938; Kaldor, 1934). This theory, initially developed to explain fluctuations in the prices and quantities in agricultural markets, emphasizes that a production adjustment to a price variation is not immediate and producers find it necessary to introduce a time delay to adjust their supply to the price on the market. We borrow this theoretical assumption and adapt it to the case of physicians.

However, in some countries, one response to medical staff shortages has been to rely on immigration. Different tools have been implemented in OECD countries to allow for the immigration of health professionals: immigration points systems that act in ways that are favourable to physicians, the renewal of visas for health professionals, the placement of health professionals on an occupational shortage list, bilateral agreements, and the recognition of diplomas from other countries (OECD, 2007; WHO, 2013). Currently, on average, foreign-trained physicians represent 17.1 per cent of the physician workforce in OECD

\footnotetext{
* Corresponding author.

E-mail addresses: xavier.chojnicki@univ-lille3.fr (X. Chojnicki), yassermoullan@wanadoo.fr (Y. Moullan).
} 
countries (OECD, 2016). The need to recruit physicians from abroad is mainly explained by: (1) the lack of support for the cost of training of a doctor (Martineau et al., 2004), (2) the inability of the educational system to ensure an equal distribution of health care workers within the country (Ono et al., 2014), and (3) the rigidity of the adjustments to medical school capacity and the time it takes to respond to a shortage (OECD, 2008). Indeed, in all OECD countries, the number of seats offered by medical schools each year is fixed (OECD, 2008). Medical associations, medical schools and governments are often involved in the regulation decisions because medical training is usually funded by public authorities. Thus, these regulations are viewed as a way to control public spending and regulate the physician workforce to satisfy the needs of the population, to ensure the healthcare quality and to guarantee the situation of active physicians (Nicholson and Propper, 2011). These regulations usually take the form of a fixed number of seats allocated to medical schools (as in France, Belgium and Germany) but can include budget constraints that limit the number of training programs (as in Australia, the UK and the US).

This paper addresses the following research questions: Do we observe any change in the number of medical graduates that are trained after an episode of a physician shortage? Do we observe an increased recruitment of foreign-trained physicians to address this shortage? Is there an emigration of physicians following the appearance of a shortage? When do these policies become effective?

Thus far, the literature has not investigated this issue because there is no clear definition of a medical shortage, and there is also a lack of data on medical graduates and on the migration of medical doctors. To address this gap in the literature, we construct a unique country-level panel dataset that includes annual data on 17 OECD countries from 1991 to 2004 comprising information on physician shortages, the number of medical school graduates and immigration and emigration rates. Our fixed effects estimates confirm that an increase in the number of medical graduates responds to a shortage only in the long run (seven to ten years after its occurrence), whereas foreign-trained physicians can arrive during the year in which a shortage occurs. Our results show evidence of the emigration of practising doctors, even during when a shortage persists. The simulation results show that the effects of reducing the shortage only through immigration are limited but that this method can be appropriate during the cycle between a shortage and surplus in the supply of physicians.

Section 2 describes the dataset used for this study. Section 3 thoroughly documents the empirical model and strategy adopted for this study. Section 4 presents the empirical results, and Section 5 provides the simulation results. Section 6 reports the main conclusions.

\section{Data}

Our country-level panel dataset allows us to track annual statistics regarding the number of graduates and the immigration and emigration of doctors in 17 OECD countries (See Table 1) from 1991 to 2004. The data on medical graduates are obtained from the OECD Health Statistics database (OECD, 2014). These data include the ratio of the number of students who graduated each year from medical schools per 1000 physicians. This variable captures the graduation rates rather than the enrolment of students, which measures the exit out of graduate study. For this reason, a delay is observed between the implementation and the effectiveness of policies through medical graduates.

The data on the international migration of physicians were obtained from Bhargava et al. (2011), which reports the stock of foreign-trained physicians inbound and outbound on an annual basis from 1991 to 2004 for the 17 OECD countries under study. These data were collected from medical associations, which provide the number of foreign-trained physicians who are registered in these countries. These data refer only to the number of licensed medical doctors ready to practice, which suits our analysis (better than the foreign-born or foreign-citizen definition) for many reasons. First, one of the tools used by OECD governments to potentially reduce shortages consists in attracting qualified physicians from abroad. This strategy is effective in the short term only if these foreign-trained physicians are permitted to practice without considerable delays caused by credential requirements. Second, focusing on the country of training avoids considering physicians who were born in a different country but educated in the destination countries as foreign physicians. Third, using the definition of country of education allows us to control for the existence of medical schools in the origin countries, which would not be possible if we used census data.

The dataset used for this study includes the annual stock of foreigntrained physicians. Ideally, flow data would be more suitable for our analysis, as they capture the entry of foreign physicians from abroad. Unfortunately, such data are not available; therefore the literature defines inflows as the difference in the stock between $t$ and $t-1$ (Beine et al., 2011). However, this measure only partially captures the inflow of physicians because entry could be due to becoming active following a break, and exit may be related to a death or other period of inactivity. Moreover, the presence of a negative value (exits are higher than entries) in a log-log model is problematic and implies that we must either ignore these flows or to replace them with a zero (Beine et al., 2011). To avoid this difficulty, we define immigration and emigration in rates rather than flows, and they are expressed per capita, which is more consistent with the structure of our econometric model which is expressed per capita. Furthermore, because we use panel-data, our analysis focuses only on the dynamics of immigration and emigration rates, which is similar to net flows over time:

Immigration rate $_{j, t}=\frac{\text { Stock immigrants }_{j, t}}{\text { Physicians }_{j, t}}$,

where $j$ represents the country and $t$ represents the year. The numerator refers to the number of foreign-trained physicians registered in the country, and the denominator refers to the total stock of physicians in the country.

The emigration rate is defined as follows:

Emigration rate $_{j, t}=\frac{\sum_{j \neq h ; h=1}^{16} \text { Stock emigrants abroad }_{j, h, t}}{\left(\text { Physicians }_{j, t}+\text { Stock emigrants abroad }_{j, t}\right)}$,

where $j$ represents the country of departure and $h$ represents the 16 other destination OECD countries. The numerator is the number of doctors registered in the 16 other destination OECD countries emigrating from country $j$ at year $t$ and the denominator is the total number of trained physicians in the country, which includes those who remain and those who emigrate. Table 1 reports the average summary statistics.

Scholars have identified different approaches to assess medical shortages (Bärnighausen and Bloom, 2011; Ono et al., 2013): the needbased approach and the demand-based approach (Scheffler et al., 2008). (i) The need-based approach bases its calculation of the level of health workforce requirements on a prediction of the level of disease among the population (Bärnighausen and Bloom, 2011). This approach considers either that disease prevalence changes only when the structure of the population changes (essentially an age and gender structure) or when there is a change in the utilisation rate. Based on these predictions, the literature derived the number of doctors required to either maximize health service targets or generate a minimum density ratio required to deliver a certain health outcome (WHO, 2006; World Bank, 1993).

(ii) The demand-based approach is mainly based on the income of the population. At the macroeconomic level, many papers highlight that the gross domestic product (GDP) or the gross national income (GNI) are the best predictors of the demand for health care (Cooper et al., 2003; Newhouse, 1977; Scheffler et al., 2008; Seale, 1959). Because health care is costly, only countries with a sufficient GDP growth rate can invest into health care. Therefore, the GDP is a predictor of expenditures related to health professionals. Second, health is a 
Table 1

Average summary from 1991 to 2004 .

\begin{tabular}{|c|c|c|c|c|c|}
\hline Country & Number of years & (Physicians/pop)*1000 & Immigration rates & Emigration rates & (Medical graduates/physicians) $* 1000$ \\
\hline Australia & 14 & 2.478 & 0.236 & 0.142 & 33.793 \\
\hline Austria & 14 & 3.646 & 0.031 & 0.044 & 46.846 \\
\hline Belgium & 14 & 3.690 & 0.171 & 0.052 & 31.530 \\
\hline Canada & 14 & 2.111 & 0.229 & 0.055 & 27.211 \\
\hline Denmark & 14 & 2.814 & 0.044 & 0.069 & 41.138 \\
\hline Finland & 14 & 2.306 & 0.071 & 0.070 & 29.238 \\
\hline France & 14 & 3.308 & 0.015 & 0.022 & 19.978 \\
\hline Germany & 14 & 3.133 & 0.037 & 0.037 & 32.289 \\
\hline Ireland & 14 & 2.221 & 0.422 & 0.540 & 54.106 \\
\hline Italy & 14 & 5.734 & 0.011 & 0.019 & 27.964 \\
\hline New Zealand & 14 & 2.097 & 0.603 & 0.269 & 31.232 \\
\hline Norway & 14 & 2.859 & 0.314 & 0.044 & 27.248 \\
\hline Portugal & 14 & 2.989 & 0.051 & 0.024 & 24.275 \\
\hline Sweden & 14 & 2.995 & 0.188 & 0.036 & 26.931 \\
\hline Switzerland & 14 & 3.325 & 0.078 & 0.052 & 25.029 \\
\hline United Kingdom & 14 & 1.896 & 0.363 & 0.102 & 38.940 \\
\hline United States & 14 & 2.221 & 0.326 & 0.003 & 26.930 \\
\hline TOTAL AVERAGE & & 2.931 & 0.206 & 0.093 & 32.040 \\
\hline
\end{tabular}

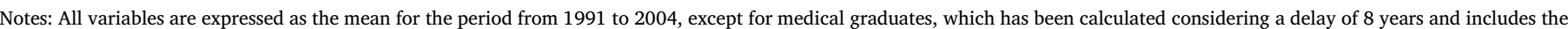

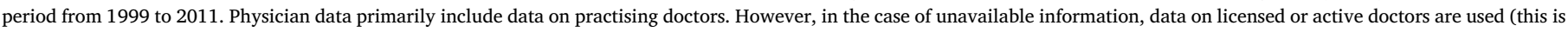
the case for Canada, France, Ireland, Italy and Portugal).

superior good; i.e., investment in the health system increases more rapidly than the GDP.

In this paper, we adopt the demand-based approach as our baseline scenario. We follow the methodology of Scheffler et al. (2008) by predicting the hypothetical required physician density based on GDP per capita, as shown the following:

$\operatorname{Ln}\left(\right.$ Predicted Physicians per $\left.1000_{j, t}\right)=\delta_{0}+\delta_{1} \operatorname{Ln}\left(\right.$ GDP per capita $\left.a_{j, t}\right)+\varphi_{j}$

$$
+\varepsilon_{j, t},
$$

where Predicted Physicians per $1000_{j, t}$ expresses the prediction of the density of doctors derived from the projection of the GDP per capita ${ }_{j, t}$, $\delta_{0}$ and $\delta_{1}$ are parameters to be estimated, $\varphi_{j}$ represents country fixed effects, and $\varepsilon_{j, t}$ is the disturbance term with a zero mean. This assumption aligns with the "pig cycle" theoretical framework proposed by Ezekiel (1938), which indicates that, on average, surpluses are compensated by shortages equal to the same quantity as if we are at equilibrium in the long term. As recommended, we use the Hoddrick-Prescott filter with a smooth parameter equal to 6.25 for annual data (Ravn and Uhlig, 2002) to exclude the 'cyclical' component of the GDP from its 'structural' component (Hoddrick and Prescott, 1997).

As robustness checks, we use the age structure of the population (proportion of people over 65 years old) and the number of consultations per year and per capita to construct an alternative measure for shortages based on the need-based approach. Then, we compare this value to the demand-based measure for shortages. We adopt the same methodology as above and estimate the following equation:

$$
\begin{aligned}
L n\left(\text { Predicted Physicians per } 1000_{j, t}\right)= & \phi_{0}+\phi_{1} L n\left(\text { Age dependency }_{j, t}\right) \\
& +\phi_{2} L n\left(\text { Consultations } j, t_{j}\right)+\varphi_{j}+\kappa_{j, t},
\end{aligned}
$$

where Age dependency $y_{j, t}$ represents the ratio of individuals over 65 to those in the 15-64 age group, and Consultations $s_{j, t}$ represents the annual number of physician visits per 1000 inhabitants.

Table 2 reports the country fixed effects estimates of equations (2.1) and (2.2), where the physician density is explained by (1) the GDP per capita (the demand-based approach), (2) the old age dependency ratio and the number of consultations (the need-based approach), and (3) considering all the variables (the mixed approach). Fig. 1 illustrates the correlation between the GDP per capita and physician density for our sample. GDP per capita is a strong determinant of the physician density, according to the literature and seems to be stronger than the old age dependency ratio and consultations, which lose their significance once
Table 2

OLS estimates of physician density by GDP per capita.

\begin{tabular}{llll}
\hline \multirow{2}{*}{ Variables } & \multicolumn{2}{l}{ Dependent variable: Ln(Physician density per 1000) } \\
\cline { 2 - 4 } & Demand based & Need based & Mixed based \\
\hline Ln(GDP per cap) in US \$ in & $0.337^{* * * *}$ & & $0.325^{* * * *}$ \\
$\quad$ PPP & $(0.0157)$ & & $\begin{array}{l}0.0181) \\
\text { Ln(Age dependency) }\end{array}$ \\
& & $0.469^{* * *}$ & 0.0661 \\
& & $(0.115)$ & $(0.0658)$ \\
Ln(Consultations) & & $0.281^{* * *}$ & $0.0644^{*}$ \\
& & $(0.0518)$ & $(0.0368)$ \\
Constant & $-2.152^{* * *}$ & $1.408^{* * *}$ & $-2.174^{* * *}$ \\
& $(0.151)$ & $(0.174)$ & $(0.213)$ \\
& & & \\
\hline Observations & 238 & 238 & 238 \\
R-squared & 0.985 & 0.946 & 0.985 \\
$\mathrm{j}$ & YES & YES & YES \\
$\mathrm{t}$ & NO & NO & NO \\
\hline
\end{tabular}

Robust standard errors in parentheses ${ }^{* * *} \mathrm{p}<0.01,{ }^{* *} \mathrm{p}<0.05,{ }^{*} \mathrm{p}<0.1$.

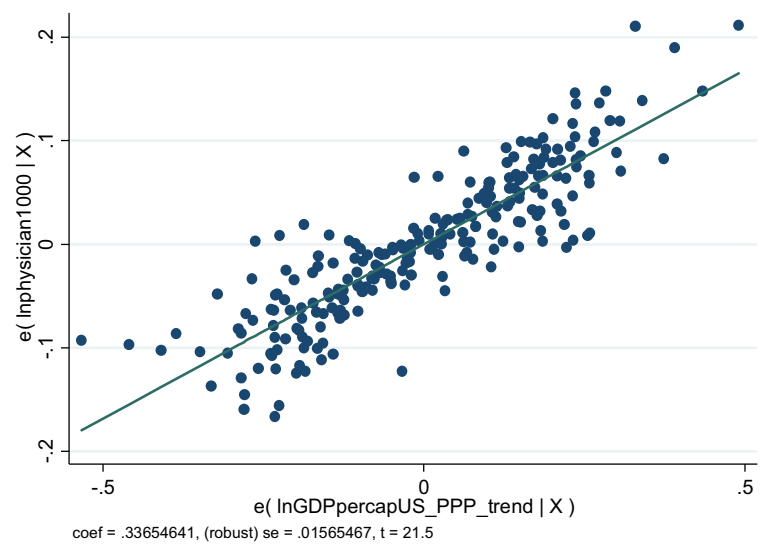

Fig. 1. Correlation between GDP per capita and physician density per 1000 people.

GDP per capita is introduced (Column 3 of Table 2). As a comparison, we observe that our $\delta_{1}$ parameter is higher but close to the coefficient of 0.237 that is reported in Scheffler et al. (2008). This difference probably occurred because we focus only on OECD countries, whereas the 
Scheffler et al. (2008) demand parameter is estimated on a world-wide sample that includes developing countries. Note that we also run a similar estimation of GDP per capita over physician density for a longterm series from 1960 to 2014 and find that coefficient $\delta_{1}$ is equal to 0.438 . Even considering these two coefficients, our results remain extremely stable, and the results are provided in table A.1 in the appendix.

In the second stage of the analysis, we use the estimated coefficients reported in Table 2 and predict the potential number of physicians for all three approaches (demand, need and mixed) for each country between 1991 and 2004. By comparing the prediction with the actual density, we can identify whether there was a shortage or surplus of physicians in the labour market. Thus, the shortage/surplus in country $j$ at time $t$ is defined as the following:

$$
\begin{aligned}
\text { Shortage }_{j, t}= & \operatorname{Ln}\left(\text { Predicted Physicians per } 1000_{j, t}\right) \\
& -\operatorname{Ln}\left(\text { Actual Physicians per } 1000_{j, t}\right)
\end{aligned}
$$

If Shortage $\mathrm{j}_{\mathrm{j}, \mathrm{t}}>0$, then the prediction (based on the demand, need or mixed approach) is higher than the observed physician density, and a shortage episode has been identified. On the other hand, if Shortage $_{\mathrm{j}, \mathrm{t}}<0$, there is a physician surplus. We report the average shortage measure for each country in Figures A.1, A.2 and A.3 in the appendix. For the vast majority of countries, the three approaches report very similar results. Next, the results will be estimated for each shortage measure.

\section{Econometric model and methodology}

Our estimated model analyses the causal relationship between the dynamics of the shortage and the policy response (medical school capacity, immigration and emigration). Thus, 3 equations are estimated:

$\operatorname{Ln}\left[\left(\frac{\text { Medical graduates }}{\text { Physicians }} * 1,000\right)_{j, t+\gamma}\right]=\alpha_{0}+\alpha_{1}$ Shortages $_{j, t}+\alpha_{2} \operatorname{Ln}\left(\mathrm{X}_{j, t}\right)+\mathrm{FE}_{j}+\mathrm{FE}_{t}+v_{j, t}$

$\operatorname{Ln}\left(1+\right.$ Immigration rate $\left._{j, t}\right)=\beta_{0}+\beta_{1}$ Shortages $_{j, t}+\beta_{2} \operatorname{Ln}\left(\mathrm{X}_{j, t}\right)+\mathrm{FE}_{j}+\mathrm{FE}_{t}+\eta_{j, t}$

$\operatorname{Ln}\left(1+\right.$ Emigration rate $\left._{j, t}\right)=\chi_{0}+\chi_{1}$ Shortages $_{j, t}+\chi_{2} \operatorname{Ln}\left(\mathrm{X}_{j, t}\right)+\mathrm{FE}_{j}+\mathrm{FE}_{t}+\mu_{j, t}$

First, we estimate the response through the number of medical graduates (equation 3.1). In alignment with the "pig cycle" theory, the dependent variable is computed with a time delay $\gamma$, which represents the time it takes to graduate from medical school (generally 8-9 years). Then, the immigration (equation 3.2) and emigration rates (equation 3.3) are estimated. These two dependent variables are defined as $1+$ variable to ensure that zero is retained in the dataset. All variables are expressed in logarithmic terms. Our variable of interest is the shortage of physicians Shortages ${ }_{j, t}$.

The control variables are included in the model through the vector $X_{j, t}$, which includes the population size, the old age dependency ratio (measured as the ratio between the number of persons at least 65 years old and the number of persons between 15 and 64 years old) (UNDP, 2012), the GDP per capita in USD purchasing power parity (PPP) (WDI, 2016), and the public social expenditures per capita in USD PPP, which refers to the generosity of the welfare system (OECD, 2014). In the model that considers increasing/decreasing the number of graduates (equation 3.1), enrolment in secondary and tertiary education, expressed as a growth rate, is introduced as a control (WDI, 2016). This variable captures any adjustments in the number of seats allotted for medical training due to the arrival of a young cohort in the educational system. In the immigration and emigration equations, two controls capture any changes in immigration policy; one captures the magnitude and the other captures the restrictiveness of immigration policies for highly-skilled individuals (DEMIG, 2014). $v_{j, t}, \eta_{j, t}$ and $\mu_{i, t}$ are the error terms for the three models. Due to the panel structure, two dummy variables are included in the analysis: country fixed effects $F E_{j}$ and time fixed effects $F E_{t}$. All explanatory and dependent variables are expressed in logarithmic form (except immigration policy variables), which induces a log-log specification. For interpreting the results, coefficients should be read as elasticity. All standard errors are clustered over the destination time dimension.

Our estimates could be subject to endogeneity issues for two reasons. First, the observed causality between the shortage and policy responses is reversed, i.e., the policy responses influence the shortage and not the opposite. This effect is mitigated for medical graduates because of the long delay (8-9 years) between the shortage and the effects of the policy. Second, any omitted variable that is correlated with our dependent variables or with the shortage variables could bias our results. The inclusion of fixed effects partially mitigated the problem of country time-invariant characteristics and year-specific omitted variables but does not protect against country time-invariant variables that were omitted. To address this issue, we use the two stage least squares (2SLS) approach. This methodology explains our shortage indicators by valid instruments, which are variables that explain the shortages without any direct links to our dependent variables. In our case, two sets of instruments are considered: the ageing of the physician workforce and regional shortages, particularly in remote areas. These are valid instruments in the sense that the ageing workforce and regional shortages trigger a policy response only through the dynamics of the shortages. In other words, because these IV have a direct effect on physician shortages, policymakers are concerned with graduating, recruiting or retaining physicians. If these IV did not have any significant effects on the aggregate shortage, policymakers would not adjust their training and immigration policies because the shortage would not change.

The first instrument used is the age dependency ratio for physicians. The data obtained from the OECD Health Statistics database includes data on the proportion of physicians by age groups and we are able to compute a ratio of physicians over 55 years old over the active physician workforce that is between 35 and 54 years old. If the physician population is ageing, there are or will be more physicians retiring in the future, which will affect the level of the physician shortage and will trigger a policy response.

The second set of instruments address the local physician density within a country, and two variables are computed for this purpose. First, the rural density ratio of physicians, which is the average number of physicians for populations living in rural areas over the last three years. Second, we include the lowest physician density in each country, which proxies the most severe regional shortage observed in a country. This indicator was obtained from the OECD's 'Region at a Glance' reports over the period under study and data were extrapolated for the missing years. These two instrumental variables capture the physician density for each country at a regional level. We consider the variations in shortages that occur within a given country (between rural and urban areas or between territories) as valid instruments for shortages that occur at the regional level, which explain national shortages at the aggregate level. High regional physician density means that health care access is easy for everyone regardless of their location (rural versus urban areas); therefore, the aggregate shortage is lower.

As robustness checks and to guard against any potential correlation between the error terms of each equation, we estimate that all equations are simultaneously related through the SURE (seemingly unrelated regression equations) methodology. The results are similar to our baseline model and are provided in table A.2 in the appendix.

\section{Empirical results}

Table 3 reports the results of the estimates of medical graduates (equation 3.1), delayed by 8 and 9 years from the time the shortage is calculated. This delay of 8-9 years corresponds to the time it takes to 


\begin{tabular}{|c|c|c|c|c|c|c|}
\hline & \multicolumn{6}{|c|}{ Dependant variable: $\ln$ (GRADUATES) 8-9 years later } \\
\hline & \multicolumn{3}{|l|}{ OLS estimates } & \multicolumn{3}{|l|}{ IV estimates } \\
\hline & Demand based & Need based & Mixed & Demand based & Need based & Mixed \\
\hline Shortage & $\begin{array}{l}0.731^{* * *} \\
(0.269)\end{array}$ & $\begin{array}{l}0.815^{* * *} \\
(0.218)\end{array}$ & $\begin{array}{l}0.820 * * * \\
(0.266)\end{array}$ & $\begin{array}{l}0.272 \\
(0.519)\end{array}$ & $\begin{array}{l}0.155 \\
(0.509)\end{array}$ & $\begin{array}{l}0.238 \\
(0.514)\end{array}$ \\
\hline Ln(Tertiary school enrolment) & $\begin{array}{l}-0.148^{*} \\
(0.0835)\end{array}$ & $\begin{array}{l}-0.145^{*} \\
(0.0784)\end{array}$ & $\begin{array}{l}-0.141 * \\
(0.0825)\end{array}$ & $\begin{array}{l}-0.274^{* * *} \\
(0.0786)\end{array}$ & $\begin{array}{l}-0.280 * * * \\
(0.0809)\end{array}$ & $\begin{array}{l}-0.276^{* * *} \\
(0.0792)\end{array}$ \\
\hline Ln(Secondary school enrolment) & $\begin{array}{l}0.137 \\
(0.114)\end{array}$ & $\begin{array}{l}0.179 \\
(0.111)\end{array}$ & $\begin{array}{l}0.139 \\
(0.113)\end{array}$ & $\begin{array}{l}0.273^{* * *} \\
(0.0994)\end{array}$ & $\begin{array}{l}0.285^{* * *} \\
(0.0958)\end{array}$ & $\begin{array}{l}0.277^{* * *} \\
(0.0980)\end{array}$ \\
\hline Ln(Population) & $\begin{array}{l}-1.664 * * \\
(0.710)\end{array}$ & $\begin{array}{l}-1.713^{* *} \\
(0.717)\end{array}$ & $\begin{array}{l}-1.741^{* *} \\
(0.712)\end{array}$ & $\begin{array}{l}-0.298 \\
(0.800)\end{array}$ & $\begin{array}{l}-0.171 \\
(0.787)\end{array}$ & $\begin{array}{l}-0.261 \\
(0.796)\end{array}$ \\
\hline Ln(Age dependency) & $\begin{array}{l}0.857^{* * * *} \\
(0.325)\end{array}$ & $\begin{array}{l}0.510 \\
(0.332)\end{array}$ & $\begin{array}{l}0.800^{* *} \\
(0.323)\end{array}$ & $\begin{array}{l}0.0283 \\
(0.303)\end{array}$ & $\begin{array}{l}0.0151 \\
(0.370)\end{array}$ & $\begin{array}{l}0.0335 \\
(0.303)\end{array}$ \\
\hline Ln(GDP per capita) & $\begin{array}{l}1.137 * * * \\
(0.278)\end{array}$ & $\begin{array}{l}1.455^{* * *} \\
(0.286)\end{array}$ & $\begin{array}{l}1.156^{* * *} \\
(0.276)\end{array}$ & $\begin{array}{l}0.520 * \\
(0.315)\end{array}$ & $\begin{array}{l}0.633^{* *} \\
(0.261)\end{array}$ & $\begin{array}{l}0.545^{*} \\
(0.295)\end{array}$ \\
\hline Ln(Social expenditures per cap) & $\begin{array}{l}0.269^{* *} \\
(0.130)\end{array}$ & $\begin{array}{l}0.250 * * \\
(0.125)\end{array}$ & $\begin{array}{l}0.266^{* *} \\
(0.128)\end{array}$ & $\begin{array}{l}0.322^{* *} \\
(0.146)\end{array}$ & $\begin{array}{l}0.302^{* *} \\
(0.137)\end{array}$ & $\begin{array}{l}0.316^{* *} \\
(0.142)\end{array}$ \\
\hline Constant & $\begin{array}{l}16.44 \\
(10.48)\end{array}$ & $\begin{array}{l}13.39 \\
(10.29)\end{array}$ & $\begin{array}{l}17.31 * \\
(10.45)\end{array}$ & $\begin{array}{l}0.878 \\
(16.36)\end{array}$ & $\begin{array}{l}-2.660 \\
(14.31)\end{array}$ & $\begin{array}{l}-0.0341 \\
(16.03)\end{array}$ \\
\hline First stage & & & & \multicolumn{3}{|c|}{ Dependent variable: Shortage } \\
\hline Ln(Age dependency physician) & & & & $\begin{array}{l}0.0903^{* * *} \\
(0.0149)\end{array}$ & $\begin{array}{l}0.0916^{* * *} \\
(0.0148)\end{array}$ & $\begin{array}{l}0.0916^{* * *} \\
(0.0158)\end{array}$ \\
\hline Ln(Physicians rural density) & & & & $\begin{array}{l}-0.122^{* * *} \\
(0.0365)\end{array}$ & $\begin{array}{l}-0.118^{* * *} \\
(0.0370)\end{array}$ & $\begin{array}{l}-0.106^{* * *} \\
(0.0399)\end{array}$ \\
\hline Controls in first stage & & & & YES & YES & YES \\
\hline Observations & 224 & 224 & 224 & 188 & 188 & 188 \\
\hline R-squared & 0.857 & 0.861 & 0.859 & 0.855 & 0.855 & 0.855 \\
\hline $\mathrm{j}$ & YES & YES & YES & YES & YES & 2.276 \\
\hline $\mathrm{t}$ & YES & YES & YES & YES & YES & YES \\
\hline Cluster & jt & jt & jt & jt & jt & $\mathrm{jt}$ \\
\hline Hansen Test (P-Value) & & & & 0.135 & 0.127 & 0.131 \\
\hline Kleibergen-Paap test & & & & 23.78 & 10.38 & 19.58 \\
\hline F-test & & & & 31.94 & 31.00 & 31.61 \\
\hline
\end{tabular}

complete medical training. We repeat the same exercise with a delay of $3-4$ years and again with a delay of 5-7 years; we find significant results only for the delay of 5-7 years, and these results are available upon request. The first three columns report the results obtained from ordinary least square (OLS) estimates. The IV estimates report the second stage, where the shortage variables are considered to be endogenous. Due to space limitations, in the first stage estimates, only the coefficients and standard errors of our instruments are reported, even when controls are included. For each methodology, we estimate the shortage using all 3 different approaches (demand, need and mixed).

As indicated by the OLS estimation, the coefficient of the shortage, regardless of which approach is used, is significantly positive at the 1 per cent significance level. As explained by the pig cycle/cobweb model, there is a time delay between the shortages and the time it takes for the medical educational system to respond, mainly due to the time it takes to complete medical training. For the demand-based variable, the magnitude of the coefficient is 0.7 , and it jumps to 0.8 when the need indicators are included. An increase of 10 per cent in the shortage indicator at time $t$ corresponds to an increase of 8 per cent in the average proportion of medical graduates (compared to the population of physicians) eight to nine years later. This coefficient loses its significance once we calculate the IV estimates. Policymakers prefer not to address shortages by increasing medical school capacity. To check IV robustness, the Hansen, F-test and Kleibergen-Paap tests are performed and confirm the validity of the instruments. The age dependency ratio, which is specific to physicians, is significantly positive, i.e., the retirement of older physicians, which will reduce the physician workforce, will worsen national shortages. The sufficient presence of physicians in rural areas leads to a decrease in national shortages.
Enrolment in tertiary education is negatively correlated with the number of students entering medical schools. As more students enrol in tertiary education, the proportion of students that study medicine decreases because medical school capacity is limited. Enrolment in secondary education is statistically positive only for the IV estimates, which suggests that the number of seats in medical schools tends to adjust to the size of the forthcoming new cohort of students. Population appears to be negatively correlated because all our econometric model (equations (3.1), (3.2) and (3.3)) use per capita values. Therefore, an increase in the population is followed by an increase in the number of physicians, which is the denominator of our graduate dependent variable. The negative sign is thus expected, and only the OLS estimates are significant. The age dependency ratio is significantly positive but only for the OLS estimates, where demand-based shortage is used. GDP per capita is significantly positive, which suggests that policy responses through the medical educational system are costly, and OECD countries adopt this policy only during periods of growth. The coefficient is higher than 1 for the OLS estimates, which indicates that health is a superior good. Social expenditures have a strong significant positive effect on the graduation rates of medical schools. High social protection maintains the level of health consumption at a high standard, which increases the number of new physicians that are trained.

Table 4 reports the estimates for the immigration rate of physicians without a time delay (results for different time delays do not show a higher rate of significance after the first year, and they can be obtained upon request). As in the previous table, the shortage variable is calculated using all 3 different approaches (demand, need and mixed). The results confirm that recruiting foreign-trained physicians takes less time to address medical shortages than training new graduates. It explains 
Table 4

Impact of the shortage on foreign-trained immigration rates with no delay.

\begin{tabular}{|c|c|c|c|c|c|c|}
\hline \multirow[t]{3}{*}{ Variables } & \multicolumn{6}{|c|}{ LN(IMMIGRATION RATE) with no delay } \\
\hline & \multicolumn{3}{|l|}{ OLS estimates } & \multicolumn{3}{|l|}{ IV estimates } \\
\hline & Demand based & Need based & Mixed & Demand based & Need based & Mixed \\
\hline Shortage & $\begin{array}{l}0.126^{* * * *} \\
(0.0442)\end{array}$ & $\begin{array}{l}0.178^{* * *} \\
(0.0305)\end{array}$ & $\begin{array}{l}0.153^{* * *} \\
(0.0418)\end{array}$ & $\begin{array}{l}0.136 * * \\
(0.0584)\end{array}$ & $\begin{array}{l}0.130 * * \\
(0.0570)\end{array}$ & $\begin{array}{l}0.133 * * \\
(0.0576)\end{array}$ \\
\hline Ln(Population) & $\begin{array}{c}-0.0259 \\
(0.0911)\end{array}$ & $\begin{array}{l}-0.0798 \\
(0.0897)\end{array}$ & $\begin{array}{l}-0.0583 \\
(0.0897)\end{array}$ & $\begin{array}{l}0.166^{*} \\
(0.0936)\end{array}$ & $\begin{array}{l}0.162^{*} \\
(0.0952)\end{array}$ & $\begin{array}{l}0.166^{*} \\
(0.0934)\end{array}$ \\
\hline Ln(Age dependency) & $\begin{array}{l}0.0154 \\
(0.0370)\end{array}$ & $\begin{array}{l}-0.0615 \\
(0.0379)\end{array}$ & $\begin{array}{l}0.00207 \\
(0.0370)\end{array}$ & $\begin{array}{l}-0.0443 \\
(0.0343)\end{array}$ & $\begin{array}{l}-0.0838 \\
(0.0476)\end{array}$ & $\begin{array}{l}-0.0467 \\
(0.0348)\end{array}$ \\
\hline Ln(GDP per capita) & $\begin{array}{l}0.0408 \\
(0.0327)\end{array}$ & $\begin{array}{l}0.112^{* * *} \\
(0.0358)\end{array}$ & $\begin{array}{l}0.0423 \\
(0.0326)\end{array}$ & $\begin{array}{l}-0.181^{* * *} \\
(0.0368)\end{array}$ & $\begin{array}{l}-0.110 * * * \\
(0.0227)\end{array}$ & $\begin{array}{l}-0.172^{* * *} \\
(0.0331)\end{array}$ \\
\hline Ln(Social expenditures per cap) & $\begin{array}{l}-0.0185 \\
(0.0179)\end{array}$ & $\begin{array}{l}-0.0201 \\
(0.0182)\end{array}$ & $\begin{array}{l}-0.0176 \\
(0.0182)\end{array}$ & $\begin{array}{l}0.0444^{*} \\
(0.0261)\end{array}$ & $\begin{array}{l}0.0378 \\
(0.0235)\end{array}$ & $\begin{array}{l}0.0424^{*} \\
(0.0254)\end{array}$ \\
\hline (Immig change level) & $\begin{array}{l}0.00335^{* * *} \\
(0.00119)\end{array}$ & $\begin{array}{l}0.00334 * * * \\
(0.00114)\end{array}$ & $\begin{array}{l}0.00328 * * * \\
(0.00118)\end{array}$ & $\begin{array}{l}0.00244 * * \\
(0.00111)\end{array}$ & $\begin{array}{l}0.00266 * * \\
(0.00106)\end{array}$ & $\begin{array}{l}0.00249 * * \\
(0.00110)\end{array}$ \\
\hline (Immig restrictiveness) & $\begin{array}{l}0.0107^{* * *} \\
(0.00332)\end{array}$ & $\begin{array}{l}0.0103^{* * *} \\
(0.00309)\end{array}$ & $\begin{array}{l}0.0105^{* * *} \\
(0.00326)\end{array}$ & $\begin{array}{l}0.00717^{* * *} \\
(0.00291)\end{array}$ & $\begin{array}{l}0.00737^{* * *} \\
(0.00278)\end{array}$ & $\begin{array}{l}0.00721^{* *} \\
(0.00288)\end{array}$ \\
\hline Constant & $\begin{array}{l}0.539 \\
(1.580)\end{array}$ & $\begin{array}{l}0.744 \\
(1.562)\end{array}$ & $\begin{array}{l}1.123 \\
(1.553)\end{array}$ & $\begin{array}{l}-1.489 \\
(1.892)\end{array}$ & $\begin{array}{l}-2.169 \\
(1.709)\end{array}$ & $\begin{array}{l}-1.577 \\
(1.864)\end{array}$ \\
\hline First stage & & & & \multicolumn{3}{|c|}{ Dependent variable: Shortage } \\
\hline Ln(Age dependency physician) & & & & $\begin{array}{l}0.0832^{* * *} \\
(0.0143)\end{array}$ & $\begin{array}{l}0.0806^{* * * *} \\
(0.0177)\end{array}$ & $\begin{array}{l}0.0834 * * * \\
(0.0148)\end{array}$ \\
\hline Ln(Lowest density) & & & & $\begin{array}{l}-0.0302^{* *} \\
(0.0120)\end{array}$ & $\begin{array}{l}-0.0406^{* *} \\
(0.0170)\end{array}$ & $\begin{array}{l}-0.0328^{* * *} \\
(0.0125)\end{array}$ \\
\hline Controls in the first stage & & & & YES & YES & YES \\
\hline Observations & 237 & 237 & 237 & 181 & 181 & 181 \\
\hline R-squared & 0.993 & 0.994 & 0.994 & 0.997 & 0.997 & 0.997 \\
\hline $\mathrm{j}$ & YES & YES & YES & YES & YES & 0.425 \\
\hline $\mathrm{t}$ & YES & YES & YES & YES & YES & YES \\
\hline Cluster & jt & jt & jt & jt & jt & jt \\
\hline Hansen Test (P-Value) & & & & 0.546 & 0.410 & 0.515 \\
\hline Kleibergen-Paap test & & & & 23.99 & 15.58 & 23.21 \\
\hline F-test & & & & 2290 & 3098 & 2423 \\
\hline
\end{tabular}

the popularity of recruiting foreign-trained doctors by its rapidity to address the shortage and saving the cost of medical training. The coefficient of the shortage is statistically positive and is 0.126 for the demand-based variables and 0.178 for the need-based variables. This result suggests that health care needs of the population require the high recruitment of foreign-trained doctors, which decreases when demand is introduced. In terms of magnitude, a 10 per cent increase in the shortage is associated with an increase of 1.26 (1.78) per cent in the immigration rate of physicians, when using the demand approach (the need-based approach). IV results show a stable coefficient around 0.13. Note that the immigration policy variables capturing restrictiveness are statistically positive with a low magnitude, which suggests that even when immigration policies for high-skilled workers are restrictive, specific measures remain in place to facilitate the recruitment of physicians. This result may have occurred because some countries use bilateral agreements, which assign extra points for health workers through a point-based system, recognize the diplomas received in other countries and place physicians on shortage lists (OECD, 2007, 2008). The results confirm that immigration policy is a weak tool to control the recruitment of physicians.

Table 5 provides the results for the emigration rate of physicians. The magnitude of the coefficient for shortage is similar for all three approaches; the demand based is 0.163 , the need based is 0.152 , and the mixed approach is 0.171 . This result is particularly notable once the IV estimates are included, even if the magnitude declines slightly to 0.11 . Our results suggest that governments fail to retain their practising physicians during shortages because a significant proportion emigrates, probably due to the burden placed on them by the shortage, which includes a deterioration in working conditions.

\section{Simulations}

Would the recruitment of immigrant doctors be enough only to address the shortage of doctors? Is a training policy that increases the number of seats in medical schools still relevant? Do changes in immigrant and emigrant rates mitigate or accentuate the observed imbalance in the physician labour market? Should one of these three instruments be specifically used to maintain the short term or long-term physician labour market equilibrium? Our main objective is to provide evidence on the reactions of our three main policy variables (e.g., number of trained doctors, immigrant doctors and emigrant doctors) to the observed or simulated evolution of the surpluses/shortages in the labour market.

Based on the elasticities of shortages that are calculated through the demand-based approach for medical school graduates, immigration and emigration (Tables 3-5), we run some simulations to predict what would have been the numbers of physicians if none of these policies (training, immigration and emigration), or only a couple of them, had been used to respond to surpluses/shortages in the physician labour market.

We build a simple dynamic model that considers the endogenous evolution of the number of doctors $\left(L_{j, t}\right)$ in each country of our sample:

$L_{j, t}=\left(1-d_{j, t}\right)\left[L_{j, t-1}+G_{j, t}+M_{j, t}-E_{j, t}\right]$,

where $G_{j, t}$ represents the number of students who graduated from medical school, $M_{j, t}$ represents the number of immigrant doctors, $E_{j, t}$ represents the number of emigrant doctors and $d_{j, t}$ represents the depreciation rate related to the death or inactivity of physicians.

The previously estimated elasticities (in Tables $3-5$ ) illustrate the 
Table 5

Impact of the shortage on the emigration rate of physicians with no delay.

\begin{tabular}{|c|c|c|c|c|c|c|}
\hline \multirow[t]{3}{*}{ Variables } & \multicolumn{6}{|c|}{ LN(EMIGRATION RATE) with no delay } \\
\hline & \multicolumn{3}{|l|}{ OLS Estimates } & \multicolumn{3}{|l|}{ IV estimates } \\
\hline & Demand based & Need based & Mixed & Demand based & Need based & Mixed \\
\hline \multirow[t]{2}{*}{ Shortage } & $0.163^{* * *}$ & $0.152^{* * *}$ & $0.171^{* * *}$ & $0.112^{* *}$ & $0.115^{* *}$ & $0.111^{* *}$ \\
\hline & $(0.0318)$ & $(0.0274)$ & $(0.0315)$ & $(0.0463)$ & $(0.0458)$ & $(0.0457)$ \\
\hline \multirow[t]{2}{*}{ Ln(Population) } & $-0.880^{* * *}$ & $-0.854 * * *$ & $-0.887^{* * *}$ & $-0.862^{* * *}$ & $-0.877^{* * *}$ & $-0.865^{* * *}$ \\
\hline & $(0.0947)$ & $(0.0898)$ & $(0.0928)$ & $(0.117)$ & $(0.112)$ & $(0.115)$ \\
\hline \multirow[t]{2}{*}{ Ln(Age dependency) } & $-0.0810^{* * *}$ & $-0.129 * * *$ & $-0.0886^{* * *}$ & $-0.128^{* * *}$ & $-0.167^{* * *}$ & $-0.131^{* * *}$ \\
\hline & $(0.0284)$ & $(0.0357)$ & $(0.0293)$ & $(0.0322)$ & $(0.0404)$ & $(0.0324)$ \\
\hline \multirow[t]{2}{*}{ Ln(GDP per capita) } & $-0.0428^{*}$ & 0.0286 & $-0.0367^{*}$ & -0.0383 & 0.0219 & -0.0308 \\
\hline & $(0.0222)$ & $(0.0223)$ & $(0.0220)$ & $(0.0331)$ & $(0.0303)$ & $(0.0315)$ \\
\hline \multirow{2}{*}{ Ln(Social expenditures per cap) } & $-0.0243^{* *}$ & $-0.0307^{* * *}$ & $-0.0253^{* *}$ & $-0.0599^{* * *}$ & $-0.0642^{* * *}$ & $-0.0613^{* * *}$ \\
\hline & $(0.0114)$ & $(0.0116)$ & $(0.0113)$ & $(0.0212)$ & $(0.0204)$ & $(0.0209)$ \\
\hline \multirow[t]{2}{*}{ (Immig change level) } & -0.00237 & -0.00215 & -0.00237 & -0.00239 & -0.00223 & -0.00236 \\
\hline & $(0.00151)$ & $(0.00146)$ & $(0.00149)$ & $(0.00163)$ & $(0.00158)$ & $(0.00162)$ \\
\hline \multirow[t]{2}{*}{ (Immig restrictiveness) } & -0.00393 & -0.00392 & -0.00402 & -0.00573 & -0.00564 & -0.00572 \\
\hline & $(0.00373)$ & $(0.00361)$ & $(0.00368)$ & $(0.00402)$ & $(0.00389)$ & $(0.00399)$ \\
\hline \multirow[t]{2}{*}{ Constant } & $17.57^{* * *}$ & $16.31 * * *$ & $17.64 * * *$ & $17.51^{* * *}$ & $17.15^{* * *}$ & $17.49 * * *$ \\
\hline & $(1.745)$ & $(1.601)$ & $(1.706)$ & $(2.247)$ & $(1.976)$ & $(2.200)$ \\
\hline & & & & \multicolumn{3}{|c|}{ Dependent variable: Shortage } \\
\hline \multirow{2}{*}{\multicolumn{4}{|c|}{ Ln(Age dependency physician) }} & $0.0832^{* * *}$ & $0.0806^{* * *}$ & $0.0834^{* * *}$ \\
\hline & & & & $(0.0143)$ & $(0.0177)$ & $(0.0148)$ \\
\hline \multirow{2}{*}{ Ln(Lowest density) } & & & & $-0.0302^{* *}$ & $-0.0406 * *$ & $-0.0328^{* * *}$ \\
\hline & & & & $(0.0120)$ & $(0.0170)$ & $(0.0125)$ \\
\hline \multicolumn{2}{|l|}{ Controls in the first stage } & & & YES & YES & YES \\
\hline Observations & 237 & 237 & 237 & 181 & 181 & 181 \\
\hline R-squared & 0.989 & 0.989 & 0.989 & 0.965 & 0.968 & 0.966 \\
\hline j & YES & YES & YES & YES & YES & 0.743 \\
\hline $\mathrm{t}$ & YES & YES & YES & YES & YES & YES \\
\hline Cluster & jt & jt & jt & jt & jt & jt \\
\hline Hansen test (P-Value) & & & & 0.371 & 0.459 & 0.389 \\
\hline Kleibergen-Paap test & & & & 23.99 & 15.58 & 23.21 \\
\hline F-test & & & & 77.27 & 89.05 & 79.90 \\
\hline
\end{tabular}

average instantaneous impact of an observed shortage on the number of trained, immigrant and emigrant doctors. But the effects are both dynamic and cumulative. The situation is dynamic in the sense that changes in the number of immigrants, graduates and emigrants, induced by a surplus/shortage situation in a given year, will change the surplus/shortage indicator in the following year, which, in turn, will affect the future evolution of the number of graduates, immigrants and emigrants. The effects are also cumulative, in the sense that an adjustment in the number of immigrants, for example, will influence the future number of trained doctors or emigrants. Moreover, when the stock of immigrants and emigrants reacts in an immediate way, the number of trained doctors reacts with some delay according to the estimated elasticities used in this study.

In the first step, our data allowed us to assign a value for each country and each year to the depreciation coefficient $d_{j, t}$. According to the current evolution of the physician labour market, which embodies the adjustments of all three policies (training, immigration and retention), we first simulate, based on significant elasticities $\alpha_{t}, \beta_{t}$ and $\chi_{t}$ (Tables 3-5), the hypothetical evolution of the number of doctors in a case where none of these policies have an effect. Then, we relax this assumption by computing the absence of adjustment for only one policy at a time (while the two other policies remain the same). We sequentially isolate the absence of the response of the training policy, the immigration policy and the emigration policy. The number of medical school graduates and immigrant and emigrant doctors are endogenously calculated for each country by assuming that our shortagesurplus indicator would not have affected these stocks of physicians:
$G_{j, t}^{c f}=\frac{\text { Medrate }_{t, j}^{c f}}{\left(1+\alpha_{1, t} \cdot \text { Shortages }_{j, t}^{c f}+\alpha_{1, t-1} \cdot \text { Shortages }_{j, t-1}^{c f}+\ldots+\alpha_{1, t-\gamma} \cdot \text { Shortages }_{j, t-\gamma}^{c f}\right)} L_{t, j}^{c f}$

$M_{j, t}^{c f}=\frac{\text { immigrate }_{t, j}^{c f}}{\left(1+\beta_{1, t} \cdot \text { Shortages }_{j, t}^{c f}+\beta_{1, t-1} \cdot \text { Shortages }_{j, t-1}^{c f}+\ldots+\beta_{1, t-\gamma} \cdot \text { Shortages }_{j, t-\gamma}^{c f}\right)}$ $L^{c f} t, j$

$E_{j, t}^{c f}=\frac{\text { emigrate }_{t, j}^{c f}}{\left(1+\chi_{1, t} \cdot \text { Shortages }_{j, t}^{c f}+\chi_{1, t-1} \cdot \text { Shortages }_{j, t-1}^{c f}+\ldots+\chi_{1, t-\gamma} \cdot \text { Shortages }_{j, t-\gamma}^{c f}\right)} M_{j, t}^{c f}$

where $G_{j, t}^{c f}, M_{j, t}^{c f}$ and $E_{j, t}^{c f}$ represent the counterfactual (cf) stocks of trained, immigrant and emigrant physicians in the case that the shortage-surplus indicator (Shortages ${ }_{j, t}^{c f}$ ) has no effect on the labour market. Next, we calculate what these rates would have been in the absence of any adjustments. The counterfactual evolution of these three factors $\left(G_{j, t}^{c f}, M_{j, t}^{c f}\right.$ and $\left.E_{j, t}^{c f}\right)$ allows us to determine how the physician stock would have evolved in each country in the absence of any adjustment due to a shortage/surplus in the physician labour market:

$L_{j, t}^{c f}=\left(1-d_{j, t}\right)\left[E^{c f}{ }_{j, t-1}+G_{j, t}^{c f}+M^{c f}{ }_{j, t}-E_{j, t}^{c f}\right]$

as well as the counterfactual endogenous surplus/shortage indicator:

Shortage $_{j, t}^{c f}=\operatorname{Ln}\left(\frac{L_{j, t}^{\text {predic }}}{1000}\right)-\operatorname{Ln}\left(\frac{L_{j, t}^{c f}}{1000}\right)$

Fig. 2 provides the aggregate results of this dynamic counterfactual experiment for all countries and Fig. 3 presents the counterfactual 


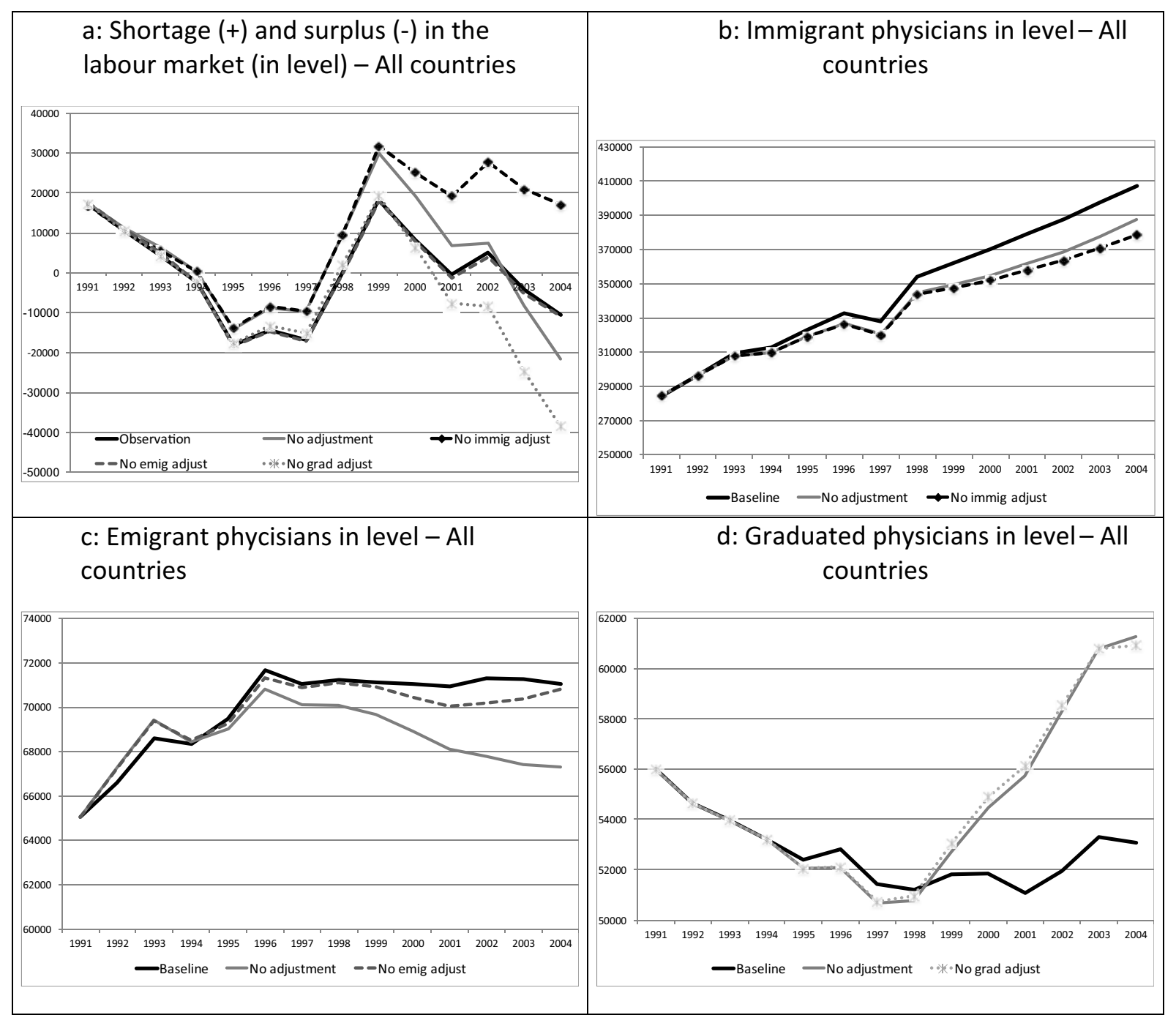

Fig. 2. Counterfactual simulations results - all countries.

evolution of the shortage/surplus indicators for six selected important countries (the US, the UK, Canada, France, Germany and Italy). Other country results are reported in the appendix. The black bold line on each figure corresponds to the observed evolution of the shortage/ surplus indicator, the number of immigrant, emigrant and graduated physicians. Thus, we observe (Fig. 2a) that over the study period, overall, the sample countries successively alternate between periods of shortages (between 1991 and 1993 and between 1999 and 2002) and surpluses (between 1994 and 1998 and between 2003 and 2004); however, each country has a unique situation (Fig. 3 and the appendix). The total number of trained doctors tends to decrease significantly between 1991 and 2001, from roughly 56,000 to 51,100 (-9\%) and increase slightly $(+4 \%)$ in the following years (Fig. $2 \mathrm{~d}$ ). The total number of immigrant doctors (Fig. 2b) continuously increases from 284,000 to 407,000 ( $+43 \%$ ). Finally, the total number of emigrant physicians significantly increased between 1991 and $1996(+10 \%)$ and then stabilized at roughly 71,000 (Fig. 2c). In total, the total number of physicians continuously increases during the study period $(+30 \%)$.

The bold grey line represents the counterfactual evolution of these variables in the case where none of the three policies reacted to changes in the surplus/shortage indicator. There is no strong adjustment in the total number of doctors following the evolution of the shortage/surplus indicator. Indeed, the counterfactual dynamics of the physician labour market are derived from the combined changes in the number of trained doctors (which would have been 16 per cent higher in 2004 -
Fig. 2d), the number of immigrant doctors (which would have been 5 per cent lower in 2004 - Fig. 2b), and the number of emigrant doctors (which would have been roughly 5 per cent lower in 2004 - Fig. 2c) in the absence of any adjustments. Therefore, the changes in these three variables tend to offset each other at the global level. These developments are far from trivial since the new domestically-trained doctors have a delayed effect. Finally, without the combined adjustment of these three variables, we find that the effect of the evolution of our dynamic imbalance indicator on the physician labour market would have been amplified, either at the global level (Fig. 2a) or for most of the countries under study (Fig. 3 and the appendix).

Finally, we disaggregate the counterfactual variations by successively neutralizing the effect of each of the three components of the evolution of the stock of doctors and assuming that the two other components still respond to the evolution of the shortage/surplus variable. For example, the black dotted lines show the evolution of the imbalance indicator in the absence of an adjustment in the number of immigrant doctors but remains unchanged according the changes in the number of graduates and emigrant doctors.

Fig. 2a clearly shows that a case that does not consider adjustments in immigration leads to a higher shortage of physicians after 1999 compared to a case where adjustments are made through graduation or emigration. This result occurs because the training of additional doctors provides a solution only in the long run and has a time delay, whereas there is an imbalance in the short term because of the time it takes for 


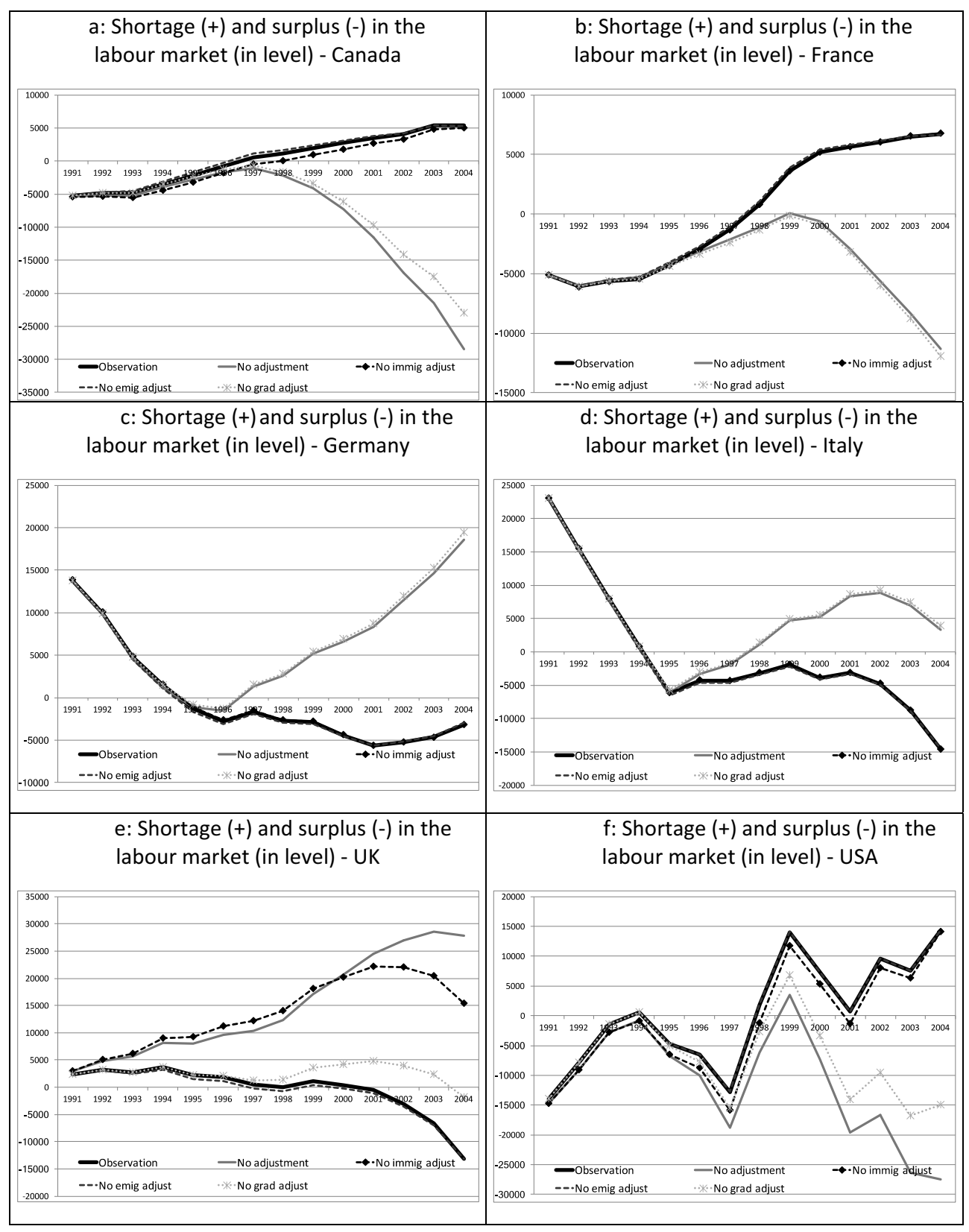

Fig. 3. Counterfactual simulations results for some specific countries.

this policy to respond. The dotted light grey line descends after 1999 (Fig. 2a), which suggests that a policy to increase physician training is likely to be effective around this time. Indeed, without any adjustments, the number of graduated physicians would have significantly increased from the numbers in 1998 (Fig. 2d). The effect of a policy of retaining physicians (emigration) is too small to expect any significant decrease in the imbalance. The aggregate policy response induced by immigration is driven by a few large countries, those traditionally characterized by a large proportion of foreign doctors (the United Kingdom, New Zealand and the USA, to a lesser extent).

In the second step, rather than starting with the observed imbalance in the labour market in each country, we now implement simple hypothetical evolutions in the shortage over time to measure how each component reacts to this shock. In contrast to the previous simulations, we do not simulate the absence of a reaction but simulate the reaction itself due to a shock that occurs in the labour market equilibrium. We complete four simulation exercises. The first scenario assumes a gradual increase in the shortage from 1991 that reaches 5 per cent of the number of doctors in 2004 in each of the countries under study (Fig. 4a). The second scenario assumes a permanent shortage of 5 per cent of the labour force in each country (Fig. 4b). The third scenario simulates a gradual increase in the shortage that reaches 5 per cent of the number of physicians in 1997 and then gradually returns to equilibrium (Fig. 4c). The last scenario simulates the opposite of the previous scenario with a shortage that decreases between 1991 and 1997 and increases again to 5 per cent of the labour force.

We successively simulate the effects of the policies, first one by one, then all together. The bold black lines correspond to the simulated shock and represents a situation without any policy adjustments. The dotted lines show the simulated shortage following an adjustment in the number of migrant doctors (black dotted line), emigrant doctors (dark dotted grey) or trained doctors (light dotted grey). The bold grey lines represent an adjustment in the shortage in a case that includes the simultaneous adjustment of the three determinants of physician stocks.

The results of these four scenarios clearly confirm the results of our first set of simulations. The immigration of foreign doctors is a better 


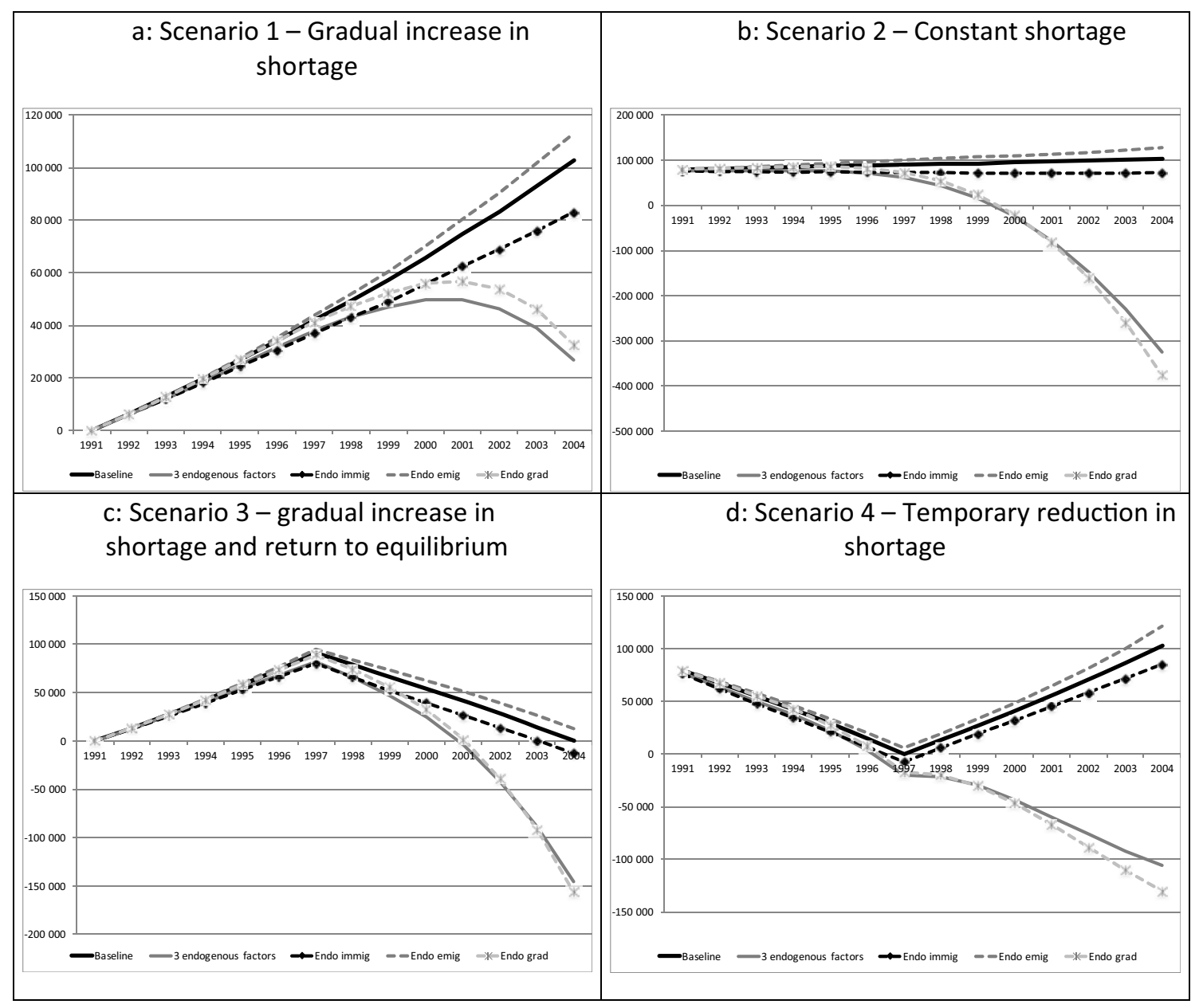

Fig. 4. Simulations results for virtual change in the surplus/shortage indicator.

short-term instrument to mitigate a shortage (whether permanent or temporary) in the physician labour market. However, in the absence of a more ambitious policy, adjustments made through migration can only partially reduce the imbalance. Only 20 per cent of the shortage can be offset by immigration. A policy that increases physician training reduces the shortage only in the case of a permanent imbalance (Scenarios 1 and 2), whereas it is not as effective when the shortage is unstable (Scenarios 3 and 4). Indeed, given the delay of the effects of a policy that increases the training of doctors, the effects occur too late and even tend to increase the degree of disequilibrium (as in the cobweb/pig cycle theory). As before, an adjustment in the number of emigrant doctors again appears; therefore, only small effects can be expected through the use of this policy.

\section{Conclusion}

This paper analyses the problem of medical shortages in developed countries. Following an episode of a medical shortage, we show that governments increase the capacity of medical schools to train more doctors. This materialises as an increase in medical graduates, on average, between eight and nine years after the appearance of the shortage. Our results also find that governments fail to retain their practising physicians during shortages because a significant proportion emigrates, probably due to the burden placed on them by the shortage, which includes a deterioration in working conditions. An immigration policy can more rapidly respond to the shortage (involving a delay of at least one year), which explains the popularity of recruiting foreigntrained physicians. Our IV estimates clearly show a preference for immigration policies over the other two policies.
The international recruitment of physicians is not without consequences for the source countries. This migration could be viewed as a 'medical brain drain' for the origin countries in the sense that they support the medical education of these individuals without benefiting from their skills once they are ready to practice (WHO, 2006). Currently, high rates of physician emigration are observed in African countries, although this region already faces severe medical shortages (Bhargava and Docquier, 2007; WHO, 2006). This situation could have detrimental effects on the health of the populations of these countries, particularly, on the efforts to address epidemics (Bhargava and Docquier, 2008).

Even if recruiting physicians from abroad seems to be a short-term solution to address shortages in developed countries, it should be in coherence with their overseas development policies to foster improved economic, social and well-being conditions in developing countries. Moreover, our simulation results show that immigration policies have a limited effect on reducing the shortage of physicians, even if it is effective for short-term adjustments. Therefore, a policy to increase the number of medical graduates seems to be the most efficient policy to reduce shortages in a sustainable manner when the shortages are not cyclical.

\section{Acknowledgements}

We would like to warmly thank the team at the International Migration Institute at the University of Oxford for their useful comments and advices. We would like to thank the participants of the 'Drivers and Dynamics of High-Skilled Migration' workshop at the University of Oxford in 2014; the 'Globalization, working conditions 
and health' international conference at the Université Montesquieu Bordeaux 4 in June 2015, the 4th Conference on Nursing and Healthcare in San Francisco in November 2015, the 5th OECD conference in Paris, the 'Changing face of Global Mobility: Celebrating 10 years of the International Migration Institute' conference at the University of Oxford in January 2016, the participants of DIAL seminar from the University of Paris Dauphine and IRDES seminars in April 2016, the participants of the workshop "International Migration of medical doctors: trends, drivers and policies" at the University of Oxford in June 2016, the European Health Economics Association (EuHEA) in Hamburg and the European Association of Labour Economics (EALE) in Ghent. Any errors that remain are our sole responsibility. The research draws on the DEMIG POLICY database, which has received funding from the European Community's Seventh Framework Programme (FP7/2007-2013)/ERC Grant Agreement 240940. Any errors that remain are our sole responsibility.

\section{References}

AAMC, 2008. In: Salsberg, M.J.D.A.E.S. (Ed.), The Complexities of Physician Supply and Demand: Projections through 2025. Association of American Medical Colleges, Center for Workforce Studies, Washington D.C.

Bärnighausen, T., Bloom, D.E, 2011. The global health workforce. In: Smith, S.G.A.P.C (Ed.), Oxford Handbook of Health Economics. Oxford University Press, Oxford.

Beine, M., Docquier, F., Özden, C., 2011. Diasporas. J. Dev. Econ. 95 (1), 30-41. http:// dx.doi.org/10.1016/j.jdeveco.2009.11.004.

Bhargava, A., Docquier, F., 2007. A New Panel Data Set on Physicians' Emigration Rates (1991-2004). Université Catholique de Louvain.

Bhargava, A., Docquier, F., 2008. HIV pandemic, medical brain drain, and economic development in sub-Saharan Africa. World Bank Econ. Rev. 22, 345-366.

Bhargava, A., Docquier, F., Moullan, Y., 2011. Modeling the effects of physician emigration on human development. Econ. Hum. Biol. 9 (2), 172-183. http://dx.doi.org/ 10.1016/j.ehb.2010.12.004

Coase, R.H., Fowler, R.F., 1935. Bacon production and the pig-cycle in Great Britain.
Economica 2 (6), 142-167.

Coase, R.H., Fowler, R.F., 1937. The pig-cycle in Great Britain: an explanation. Economica 4 (13), 55-62.

Cooper, R.A., Getzen, T.E., Laud, P., 2003. Economic expansion is a major determinant of physician supply and utilization. Health Serv. Res. 38 (2), 675-696. http://dx.doi. org/10.1111/1475-6773.00139.

DEMIG, 2014. Demig policy database.

Ezekiel, M., 1938. The cobweb theorem. Q. J. Econ. 52 (2), 255-280.

Hoddrick, R.J., Prescott, E.C., 1997. Postwar U.S. Business cycles: an empirical investigation. J. Money Credit Bank. 29 (1), 1-16.

Kaldor, N., 1934. A classificatory note on the determinants of equilibrium. Rev. Econ. Stud. 1 (2), 122-136.

Martineau, T., Decker, K., Bundred, P.E., 2004. "Brain drain" of health professionals: from rhetoric to responsible action. Health Pol. 70, 1-10.

Newhouse, J.P., 1977. Medical-care expenditure: a cross-national survey. J. Hum. Resour. 12 (1), 115-125.

Nicholson, S., Propper, C., 2011. Medical workforce. In: In: Pauly, M.V., McGuire, T.G., Barros, P.P. (Eds.), Handbook of Health Economics, vol. 2 (North Holland).

OECD, 2007. Immigrant health workers in OECD countries in the Broader context of highly skilled migration. In: OECD-SOPEMI (Ed.), International Migration Outlook 2007, pp. 161-228 (Paris).

OECD, 2008. The Looming Crisis in the Health Workforce, How Can OECD Countries Respond? OECD HEALTH POLICY STUDIES. OECD.

OECD, 2014. Health OECD Data.

OECD, 2016. Health Workforce Policies in OECD Countries: Right Jobs, Right Skills, Right Places OECD Health Policy Studies. OECD, Paris.

Ono, T., Lafortune, G., Schoenstein, M., 2013. Health Workforce Planning in OECD Countries: a Review of 26 Projection Model from 18 Countries, vol. 62. pp. 1-130 OECD Health Working Papers.

Ono, T., Schoenstein, M., Buchan, J., 2014. Geographic Imbalances in Doctor Supply and Policy Responses. OECD Health Working Papers, (69). Paris.

Ravn, O.M., Uhlig, H., 2002. On adjusting the Hoddrick-Prescott filter for the frequency of observations. Rev. Econ. Stat. 84 (2), 371-380.

Scheffler, R.M., Liu, J.X., Kinfu, Y., Dal Poz, M.R., 2008. Forecasting the global shortage of physicians: an economic- and needs-based approach. Bull. World Health Organ. 86 (7), 516B-523B.

Seale, J.R., 1959. A general theory of national expenditure on medical care. Lancet 2 (7102), 555-559.

UNDP, 2012. World Population Propects.

WDI, 2016. World Development Indicators.

WHO, 2006. Working together for health. In: W. H. Organization (Ed.), World Health Report. World Health Organization, Geneva.

WHO, 2013. In: W. R. O. f. Europe (Ed.), WHO Policy Dialogue on International Health Workforce Mobility and Recruitment Challenges: Technical Report. WHO, Denmark. World Bank, 1993. In: O. U. Press (Ed.), Investing in Health. World Bank, New York. 